\title{
Measurement of Relative Permeability Curves of Cores with Different Permeability and Lengths under Unsteady-State
}

\author{
Haixia $\mathrm{Hu}^{1}$, Wei Luo $^{2 *}$, Qinghua Wang ${ }^{3}$, Junzheng Yang ${ }^{3}$, Xiaoyan Zhang ${ }^{3}$, Zhonghao Li $^{2}$, Xuanhao Zhang ${ }^{2}$ \\ ${ }^{1}$ College of Technology \& Engineering, Yangtze University, Jingzhou 434000, China \\ ${ }^{2}$ Petroleum Engineering Institute, Yangtze University, Wuhan 430100, China \\ ${ }^{3}$ PetroChina Research Institute of Petroleum Exploration \& Development, Beijing 100083, China
}

Corresponding Author Email: luowei16@yangtzeu.edu.cn

https://doi.org/10.18280/ijht.390124

Received: 17 September 2020

Accepted: 25 December 2020

\section{Keywords:}

unsteady-state, relative permeability curve, oil-water, gas-water, core length, isopermeability point

\begin{abstract}
The oil-water and gas-water relative permeability curves are important reference data for the dynamic analysis and numerical simulation of oil and gas reservoir exploitation. Although the petroleum industry of China and other countries have formulated reference standards for the measuring methods of relative permeability of cores, they haven't given the definite reference values of the core length, therefore we cannot know for sure whether different core length values are required in the measurement and whether the core length has an impact on the measurement results. In view of this gap, this paper conducted a research on the relative permeability of cores with different lengths. The core samples are artificial core with similar properties as the outcrop cores of the Halfaya Oilfield (Iraq), in our experiment, the oil-water and gas-water relative permeability curves of the sample cores were measured and the results suggest that, for the oil-water relative permeability curves, as the core length grows, the iso-permeability points move to the right, and they basically stabilize when the core length is greater than $20 \mathrm{~cm}$; as for gas-water relative permeability curves, in case of low-permeability cores, under constant injection pressure, as the core length grows, the iso-permeability points and the two-phase co-permeation areas present an obvious tendency of moving to the left, but when the core length is greater than $20 \mathrm{~cm}$, such tendency is not obvious, and the high-permeability cores do not have such characteristics. These results indicate that, the unsteady-state two-phase relative permeability measurement experiments obtained accurate results at a core length of about $20 \mathrm{~cm}$, which provided a reference for similar experiments in subsequent research.
\end{abstract}

\section{INTRODUCTION}

Field scholars have done a lot research on the relative permeability of two-phase fluids and obtained fruitful results. Foreign studies started earlier in this aspect, for instance, scholars found through experiments that when two-phase fluids flow in a porous medium at the same time, the permeability of each phase will be greatly reduced due to the Jamin effect [1-3]. In 1937, Muskat et al. found for the first time that for a same core, the permeability value measured with gas flow is generally higher than that measured with fluid flow, and the lower the core permeability, the more obvious the difference. After that, scholar Klinkenberg proposed the slippage effect of gas in micro-diameter tube flows. The research of scholar Leverett and others suggested that the relative permeability of water and gas phases is a function of their respective saturation [4-6]. Esmaeili et al. [7] reviewed the results of previous studies on the impact of temperature on the two-phase relative permeability, and proposed that it's not appropriate to generalize the impact of temperature on relative permeability, they also pointed out that the relative permeability of a particular oil reservoir may (or may not) change with temperature. Lai and Miskimins [8] explored a new technique for measuring the two-phase relative permeability under non-Darcy flow conditions and their results showed that the relative permeability calculated by the
non-Darcy flow model for gas is higher than that calculated by the Darcy flow model. In addition, experiments on the impact of confining pressure on the gas-water relative permeability also indicate that, as the confining pressure increases, the gasphase relative permeability decreases significantly, but its impact on the water-phase relative permeability is not obvious.

In China, the research on two-phase relative permeability started relatively late. In existing studies, scholars Ren et al. [9] found through experiments that when there's residual water in low-permeability cores, the flow pattern of gas in the core is related to core permeability, water saturation, and pressure gradient. Jiang et al. studied on the characteristics of gas-water relative permeability and found that the inaccuracy and distortion of the reference permeability is one of the reasons that the gas-phase relative permeability is greater than 1. Based on the Thomas model and taking the start-up pressure gradient into consideration, Wang et al. [10] established a 3D gas-water two-phase full-implicit permeation model for lowpermeability fractured gas reservoirs. Yi et al. [11] designed a back-pressure device for the measurement of the relative permeability of high-temperature and high-pressure unsteadystate water-displaced gas, breaking through the limitation that the relative permeability curve of water-displaced gas can only be achieved via the steady-state method, and the measurement has the merits of fast and accurate [12]. Dong et al. [13] studied the characteristics of multi-phase permeation under certain 
formation temperature and pressure conditions, and obtained the permeability curves of oil-gas, oil-water and gas-water multi-phase permeation; their results showed that, under certain formation conditions, the oil-water, oil-gas, and gaswater two-phase permeability of low-porosity and lowpermeability rocks is relatively weak; but for high-porosity and high-permeability rocks with fractures or pores, the copermeation areas of oil-water, oil-gas, and gas-water are relatively wide, and the displacement efficiency is higher.

Domestic and foreign studies on the relative permeability curve mostly focused on temperature, pressure, physical properties of the reservoir, and permeation conditions, few of them concerned about the impact of core length on the measurement results of relative permeability curves. Dong et al. [13] mentioned in their study that using unsteady-state method to study relative permeability is not adaptable since the end effect is obvious and longer samples are required, however, the length of most samples is less than $6 \mathrm{~cm}$, so the end effect cannot be eliminated. At present, in most laboratories, the cores used for the measurement of relative permeability curves have two types: small cores (diameter is about $2.5 \mathrm{~cm}$ ) and full-diameter cores (diameter is about $6 \mathrm{~cm}$ ), the length of the cores is generally about $5-10 \mathrm{~cm}$ [14-16], and very few researches use long cores to measure the relative permeability curves. Therefore, this paper selected the artificial long cores with similar characteristics as the outcrop cores of the Halfaya Oilfield for indoor simulation experiments. For core samples of different permeability and lengths, unsteady-state experiments were performed to measure and analyze the oil-water and gas-water relative permeability curves, in the hopes of providing a reference for similar experiments in subsequent research, and offering a theoretical basis and instructions to the numerical simulation of study areas and the formulation of development plans [17, 18]. This paper has four parts: experiment content; experiment principle, process and steps; experimental data processing and result analysis; and conclusions.

\section{EXPERIMENT CONTENT}

In the experiment, three permeability values $(10 \mathrm{mD}, 50 \mathrm{mD}$, $100 \mathrm{mD}$ ) were selected for the artificial core samples, and for each type of core samples, three lengths $(10 \mathrm{~cm}, 20 \mathrm{~cm}, 30 \mathrm{~cm})$ were selected, the core diameter was $2.5 \mathrm{~cm}$, and the core experiments were arranged as shown in Table 1.

Table 1. Arrangement of the experiments

\begin{tabular}{|c|c|c|c|c|}
\hline Experiment type & Experiment condition & Core length/cm & Permeability/mD & Core No. \\
\hline \multirow{6}{*}{ Displacing oil with water } & \multirow{6}{*}{ Constant speed } & \multirow{2}{*}{10} & 50 & $50-1$ \\
\hline & & & 100 & $100-1$ \\
\hline & & \multirow{2}{*}{20} & 50 & $50-2$ \\
\hline & & & 100 & $100-2$ \\
\hline & & \multirow{2}{*}{30} & 50 & $50-3$ \\
\hline & & & 100 & $100-3$ \\
\hline \multirow{20}{*}{ Displacing water with gas } & \multirow{4}{*}{ Constant pressure $0.1 \mathrm{MPa}$} & 20 & 100 & $100-2$ \\
\hline & & \multirow{2}{*}{30} & 50 & $50-3$ \\
\hline & & & 100 & $100-3$ \\
\hline & & \multirow{3}{*}{10} & 10 & $10-1$ \\
\hline & \multirow{8}{*}{ Constant pressure $0.2 \mathrm{MPa}$} & & 50 & $50-1$ \\
\hline & & & 100 & $100-1$ \\
\hline & & \multirow{3}{*}{20} & 10 & $10-2$ \\
\hline & & & 50 & $50-2$ \\
\hline & & & 100 & $100-2$ \\
\hline & & \multirow{3}{*}{30} & 10 & $10-3$ \\
\hline & & & 50 & $50-3$ \\
\hline & & & 100 & $100-3$ \\
\hline & \multirow{4}{*}{ Constant pressure $0.3 \mathrm{MPa}$} & \multirow{2}{*}{20} & 10 & $10-2$ \\
\hline & & & 100 & $100-2$ \\
\hline & & \multirow{2}{*}{30} & 50 & $50-3$ \\
\hline & & & 100 & $100-3$ \\
\hline & \multirow{4}{*}{ Constant pressure $0.4 \mathrm{MPa}$} & \multirow{3}{*}{20} & 10 & $10-2$ \\
\hline & & & 50 & $50-2$ \\
\hline & & & 100 & $100-2$ \\
\hline & & 30 & 10 & $10-3$ \\
\hline
\end{tabular}

\section{EXPERIMENT PRINCIPLE, PROCESS, AND STEPS}

The measurement of oil-water relative permeability using the unsteady-state method is based on the Buckley-Leverett one-dimensional two-phase water-displaced oil front-advance theory. In the experiment, capillary pressure and gravity were ignored, and it's assumed that the two-phase immiscible fluids were incompressible, and the oil-water saturation in any cross section of the rock samples was uniform. In the experiment, the core samples were saturated with one fluid in advance and then displaced with another fluid. In the process of displacing oil with water, the distribution of oil-water saturation in porous media is a function of distance and time. This process is an unsteady process. The principle for measuring the gas-water relative permeability using the unsteady-state method is the same.

\subsection{Experiment process}

The experiment equipment includes: core holder, pressure 
sensor, liquid measuring cylinder, six-way valve, intermediate container, nitrogen gas cylinder, hand-operated confining pressure pump, constant-flux pump, valves, and wet gas flow meter. The experiment process is shown in Figure 1. Some artificial long core samples are shown in Figure 2.

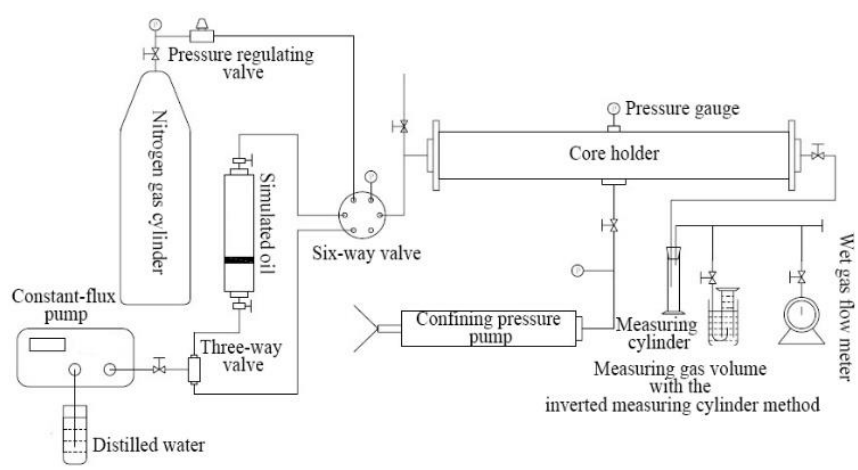

Figure 1. Experiment process

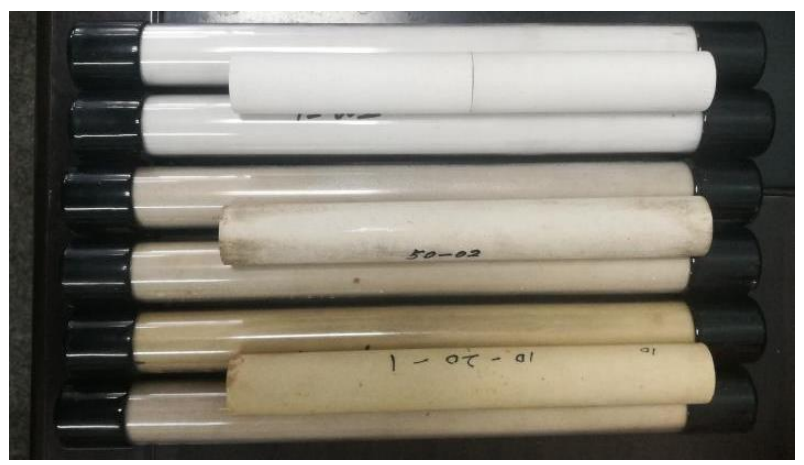

Figure 2. A photo of some artificial core samples

\subsection{Experiment steps for measuring oil-water relative permeability using the unsteady-state method}

The core samples used in the experiment were artificial and the oil was $5 \#$ white oil with a viscosity of $12.4 \mathrm{mPa} \cdot \mathrm{s}$ and a density of $0.858 \mathrm{~g} / \mathrm{cm}^{3}$, the oil was subject to vacuum filtration before the experiment; to avoid core pollution, distilled water was used in the experiment, and the specific experiment steps are:

(1) The main material of the artificial core is quartz sand, organic materials were added in the quartz sand and cemented, and a certain amount of clay minerals were mixed, then, some silicone oil was added to adjust the wettability to neutral wet or weak water wet; after that, the materials were put into molds to shape, and then placed into a constant temperature oven to bake, later, they were cut into the length required for the experiment.

(2) The core samples were dried and weighed for their dry weight, and then measured for gas permeability.

(3) The core samples were vacuumed for 4 hours, then the formation water was sucked into the vacuum chamber and saturated for 3 hours, after that, the core samples were taken out and weighed for wet weight, and the pore volume and porosity were calculated;

(4) Distilled water was used to measure the permeability of the core with water flow at a certain flow rate;

(5) Oil was used to displace the distilled water in the cores to create irreducible water saturation. In the beginning, the displacement was at a low speed of $0.1 \mathrm{ml} / \mathrm{min}$, then the displacement speed was gradually increased until it reached the displacement speed set for the experiment and no water had come out for a while, the displacement pressure difference and permeability with fluid flow were measured at this time (the state at this moment was that the water had been displaced by oil). After displacement, the core samples were immersed in simulated oil and aged in the constant temperature oven for some time.

(6) According to the experiment plan, the core displacement experiment was performed, time, displacement pressure difference, accumulated oil output, and accumulated fluid output were recorded; at the initial stage (when samples just contacted with water), the records were more frequent (in shorter time intervals), then with the decrease of the oil output, the record time intervals were longer, at last, the experimental results were calculated.

\subsection{Experiment steps for measuring gas-water relative permeability using the unsteady-state method}

(1) Core samples were installed in the core holder, then the constant-flux pump was used to perform water displacement on core samples at a certain flow rate, and the water-phase permeability was measured consecutively for 3 times (after the inlet-outlet pressure difference of the core samples and the outlet flow were stable), the relative error of the 3 measurements was less than 3\%. The average permeability was taken as the basic value of gas-water relative permeability.

(2) According to the permeability measured with gas flow and water flow, an appropriate displacement pressure difference was selected, the initial pressure difference must be able to overcome the end effect and not produce turbulence. The initial gas displacement pressure was $0.1 \mathrm{MPa} \sim 0.6 \mathrm{MPa}$.

(3) The experiment of displacing water with gas was started, the displacement pressure, liquid output, and gas output were recorded at designed time intervals; at the initial stage (when samples just contacted with water), the data were recorded at shorter time intervals, then with the decrease of the liquid output, the record time intervals became longer, at last, the experimental results were calculated.

(4) The experiment of displacing water with gas was continued until the there's only residual water, after the gasphase effective permeability was measured, the experiment terminated.

(5) The gas-phase effective permeability was measured under the residual water states (the measurement was conducted under $1 / 2$ and $1 / 4$ displacement pressure respectively), and whether turbulence had occurred or not was judged (turbulence would occur when the effective permeability under low pressure exceeds $10 \%$ of the effective permeability under displacement pressure).

\section{DATA PROCESSING AND RESULT ANALYSIS}

\subsection{Processing of experimental data}

According to the Petroleum and Natural Gas Industry Standard of the People's Republic of China SY/T5345-2007 Test Method for Two-Phase Relative Permeability in Rocks [19], the experimental data were processed to get oil-water and gas-water relative permeability under different core permeability and core length conditions. After data processing, abnormal data points were eliminated and the curves of oilwater and gas-water relative permeability were plotted. 
4.2 Analysis of experimental results of oil-water relative permeability curves measured by unsteady-state method

As shown in Figure 3, after the displacement started, with the increase of water saturation, the oil-phase relative permeability gets worse significantly, and the water-phase relative permeability gets better significantly. As the core length grows, the iso-permeability points move to the right. But when the core length is greater than $20 \mathrm{~cm}$, the isopermeability points are basically stable, indicating that the core length has an impact on the measurement results of the oil-water relative permeability curve.

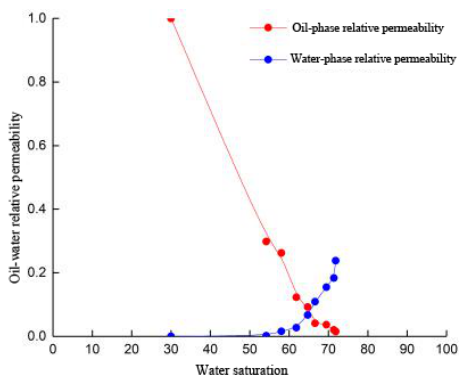

$50-1$

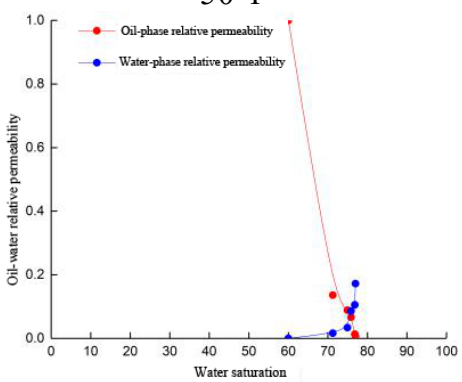

$100-1$

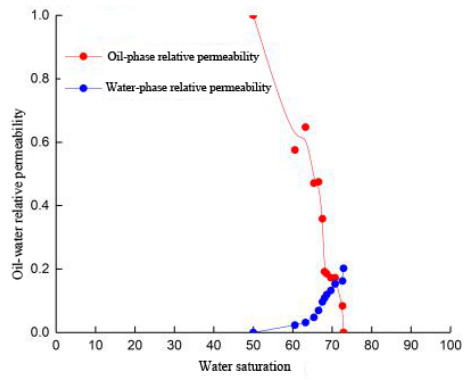

$50-2$

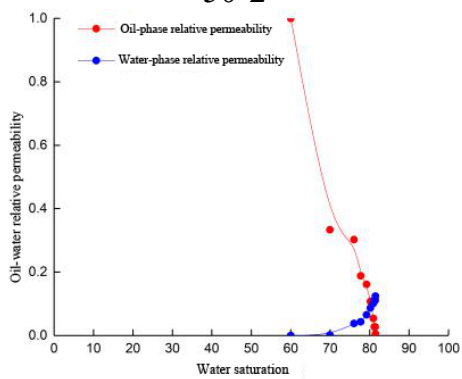

$100-2$

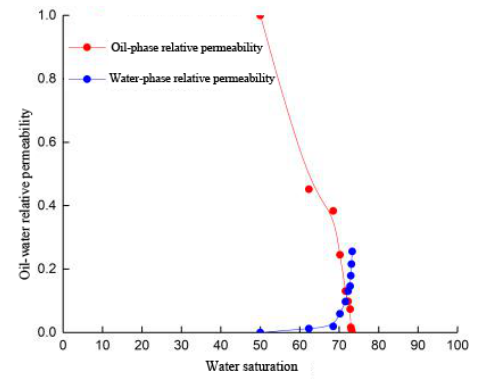

$50-3$

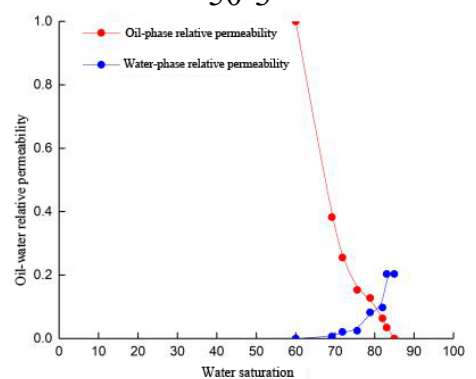

$100-3$

Figure 3. Oil-water relative permeability curves

\subsection{Analysis of experimental results of gas-water relative} permeability curves measured by unsteady-state method

Under a constant pressure of $0.1 \mathrm{MPa}$, the results of the experiment of displacing water with gas at unsteady-state are shown in Figure 4.

Under a constant pressure of $0.2 \mathrm{MPa}$, the results of the experiment of displacing water with gas at unsteady-state are shown in Figure 5.

Under a constant pressure of $0.3 \mathrm{MPa}$, the results of the experiment of displacing water with gas at unsteady-state are shown in Figure 6.

Under a constant pressure of $0.4 \mathrm{MPa}$, the results of the experiment of displacing water with gas at unsteady-state are shown in Figure 7.

According to Figure 4-7, under the conditions of different injection pressure, core permeability, and core length values, after the displacement starts, with the increase of gas saturation, the water-phase relative permeability curves show a steep decline in the initial stage, and the decline gradually slows down in later stage. As shown in Figure 5, when injection pressure is constant and the core permeability is $10 \mathrm{md}$ and $50 \mathrm{md}$, as the core length grows, the iso-permeability points and the co-permeation areas obviously move to the left, showing the characteristics of increased hydrophilicity, but such characteristics is not obvious when the core permeability is $100 \mathrm{md}$, this indicates that during the measurement of relative permeability, for low-permeability cores, the core length has an impact on the measurement results of relative permeability curves; when the core length is about $20 \mathrm{~cm}$, the measurement results are relatively accurate. For highpermeability cores, the impact of core length on the measurement results of relative permeability curves is not obvious.
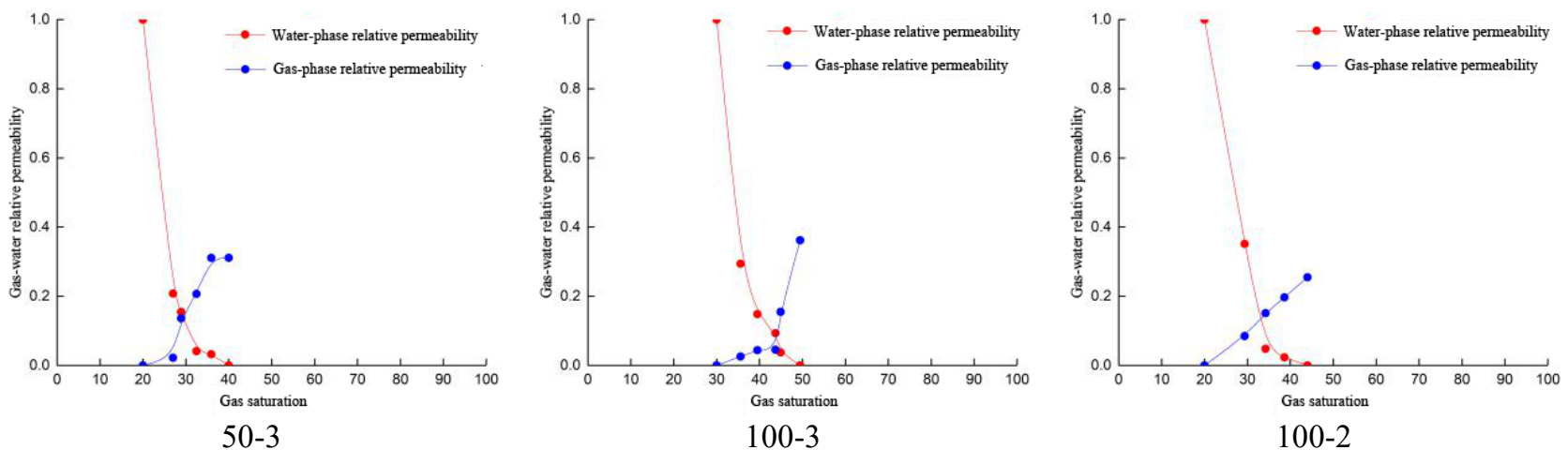

Figure 4. Unsteady-state gas-water relative permeability curves under a constant pressure of $0.1 \mathrm{Mpa}$ 


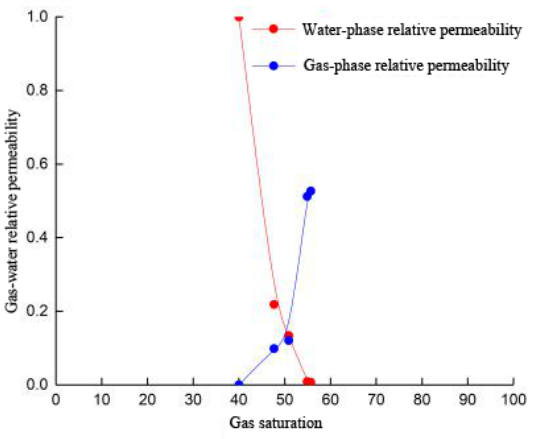

10-1

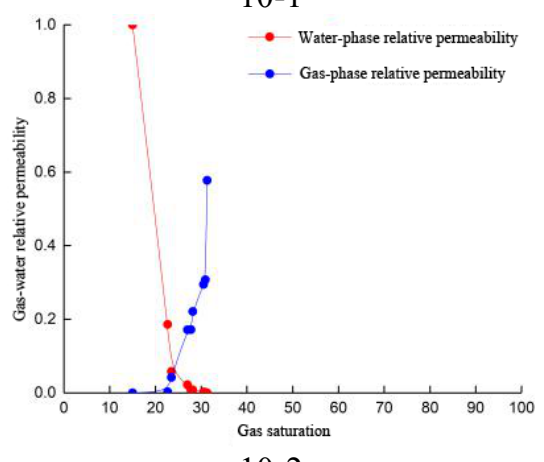

10-2

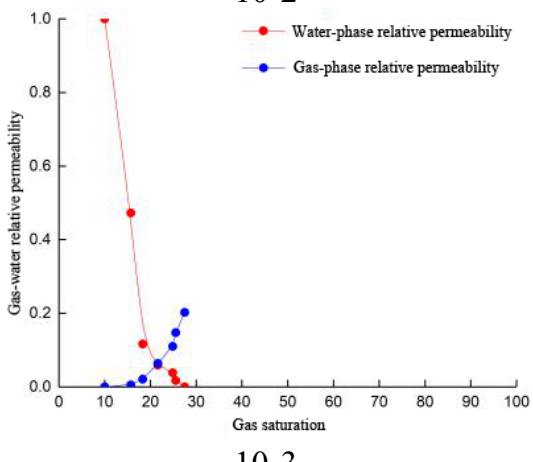

10-3

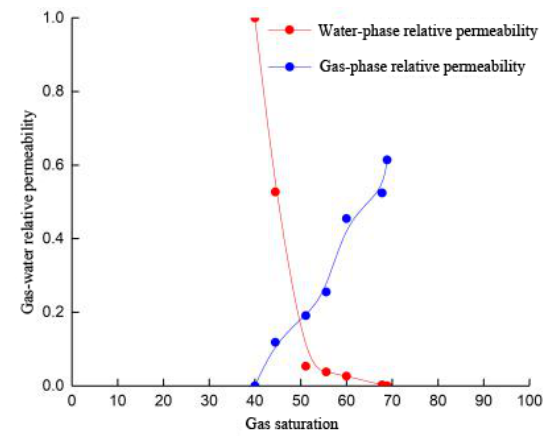

50-1

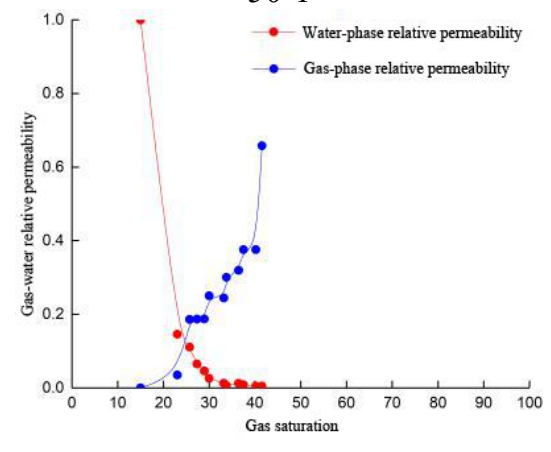

50-2

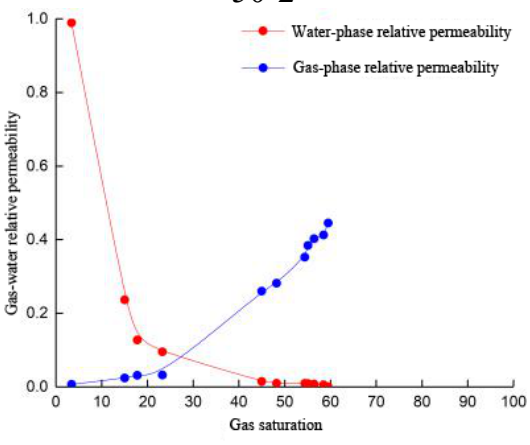

50-3

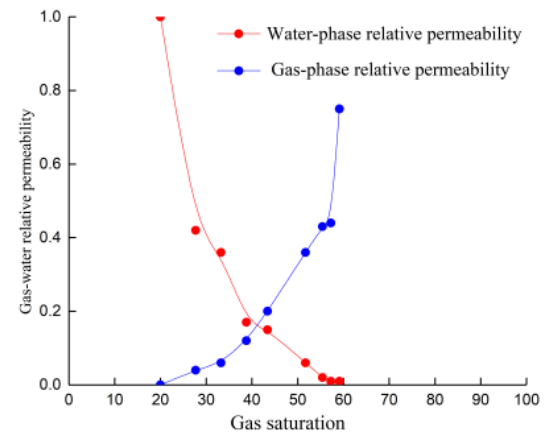

100-1

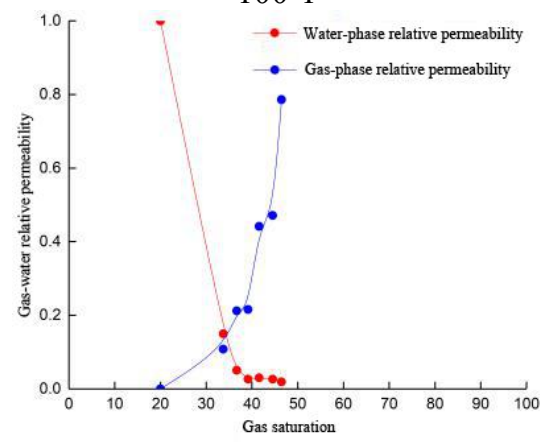

100-2

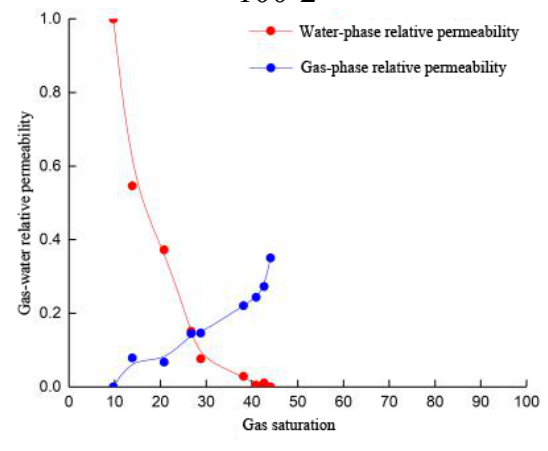

100-3

Figure 5. Unsteady-state gas-water relative permeability curves under a constant pressure of $0.2 \mathrm{MPa}$
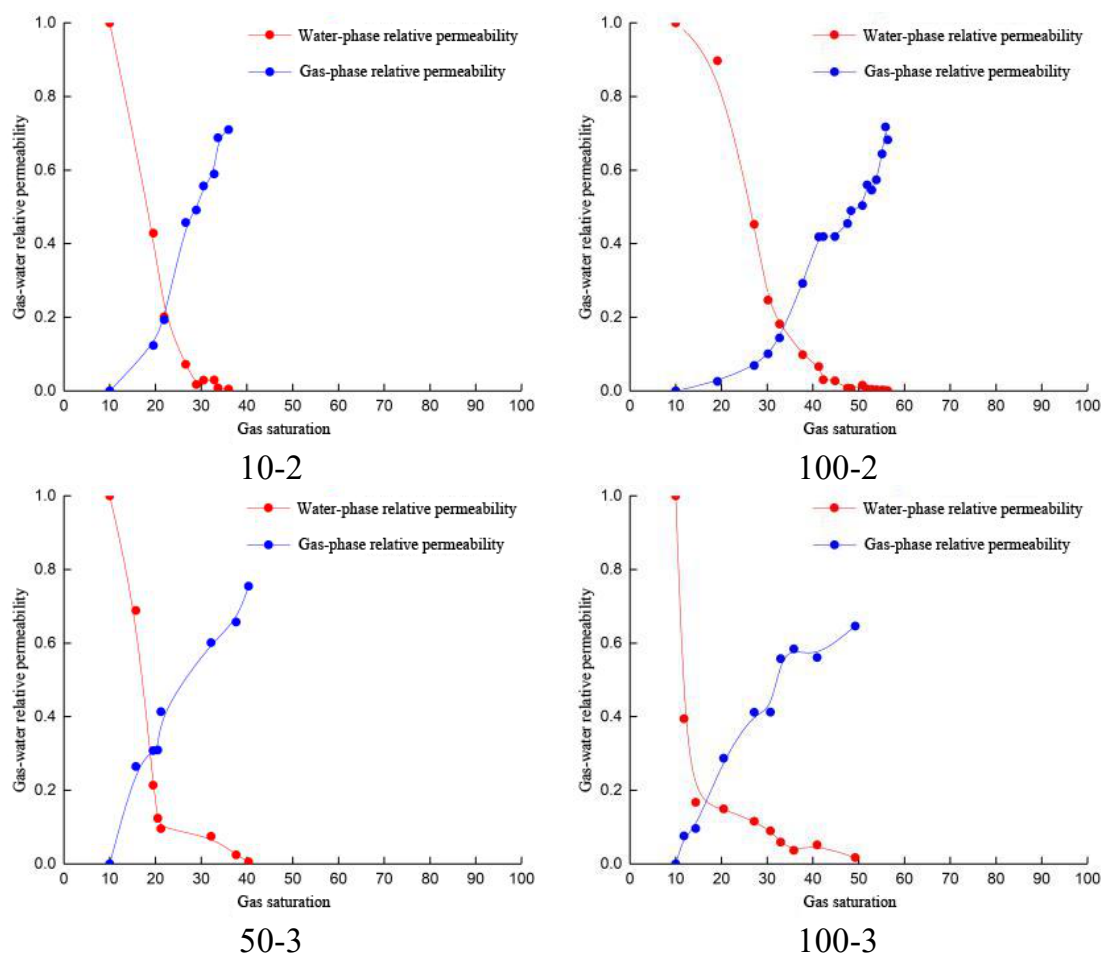

Figure 6. Unsteady-state gas-water relative permeability curves under a constant pressure of 0.3Mpa 
As shown in Figure 8, when injection pressure and core length are constant, as the core permeability increases, the gasliquid relative permeability increases as well, the isopermeability points tend to move to the right, and the gasliquid co-permeation areas increase.

As shown in Figure 9, when core permeability and core length are constant, for low-permeability cores, as the injection pressure grows, the gas-water co-permeation areas increase, the gas-water relative permeability increases, and the curves move to the right. As for high-permeability cores, within a certain pressure range, the gas-water co-permeation areas increase; when the pressure continues to grow, the gaswater co-permeation areas do not change much.

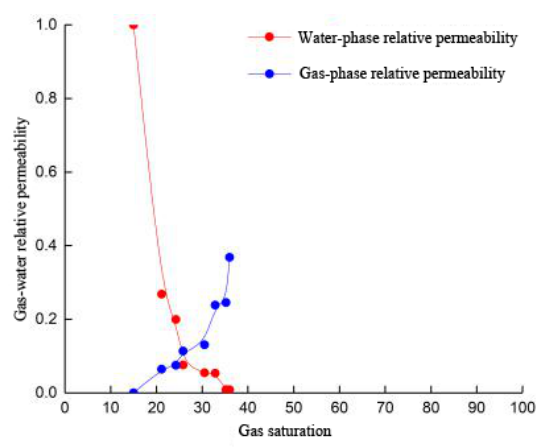

10-3

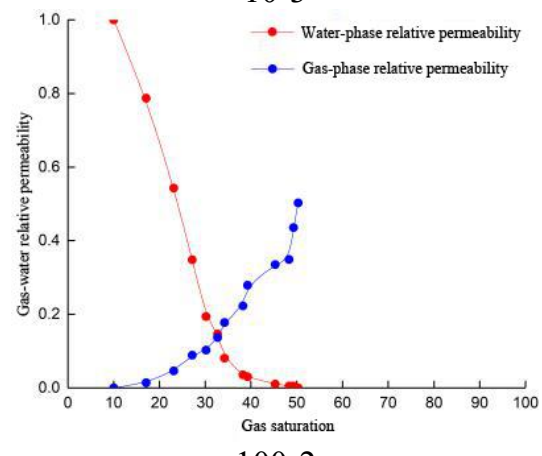

$100-2$

Figure 7. Unsteady-state gas-water relative permeability curves under a constant pressure of 0.4Mpa
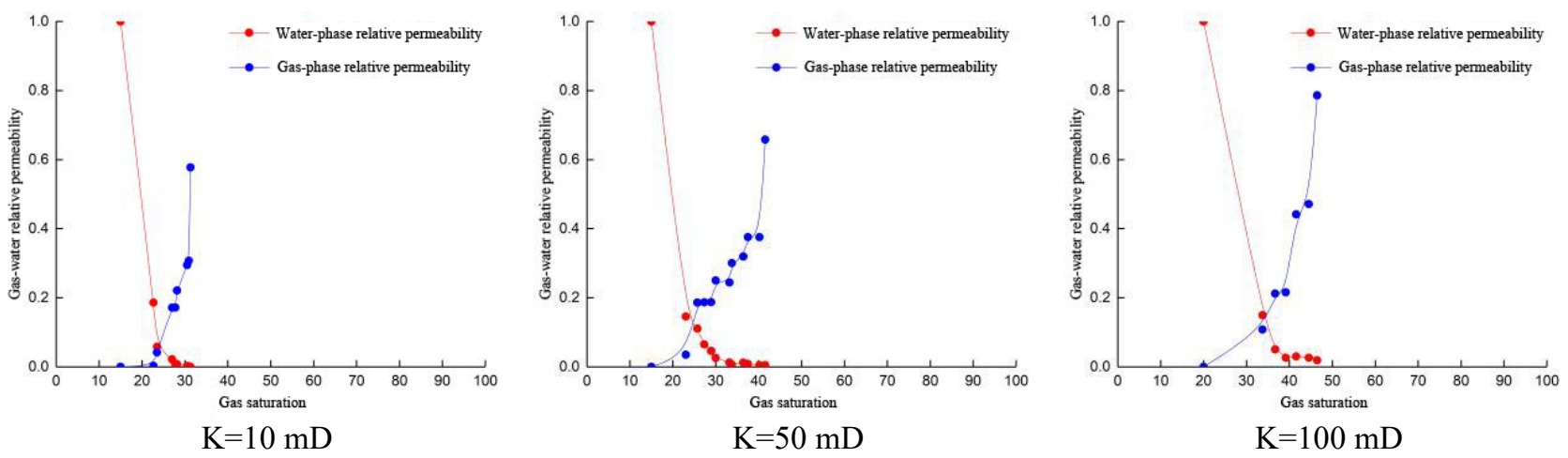

Figure 8. Comparison of relative permeability curves under an injection pressure of $0.2 \mathrm{MPa}$ and a core length of $20 \mathrm{~cm}$

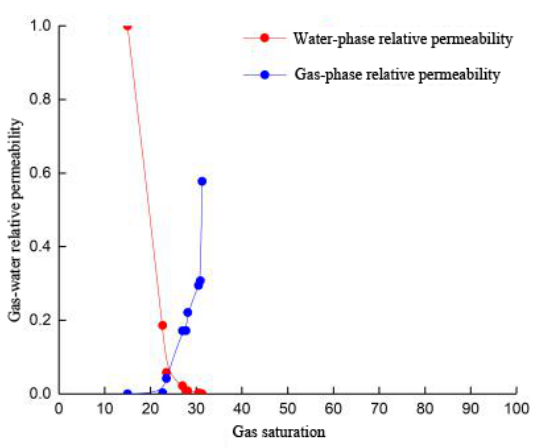

$\Delta P=0.2 \mathrm{Mpa}, \mathrm{K}=10 \mathrm{mD}$

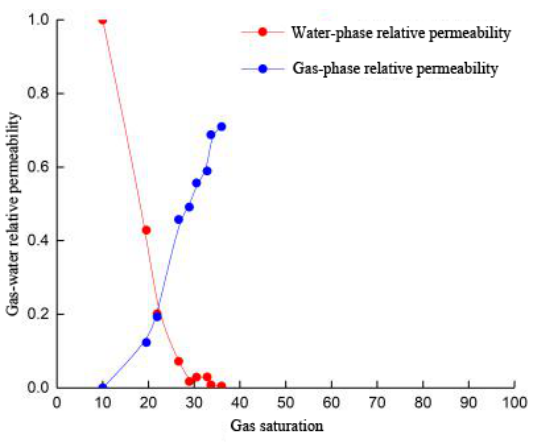

$\Delta P=0.3 \mathrm{Mpa}, \mathrm{K}=10 \mathrm{mD}$

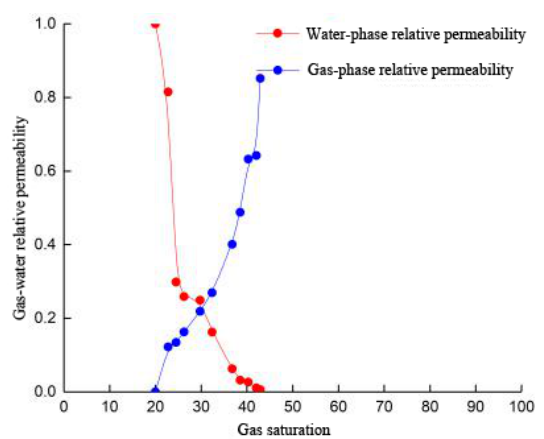

$\Delta P=0.4 \mathrm{Mpa}, \mathrm{K}=10 \mathrm{mD}$ 

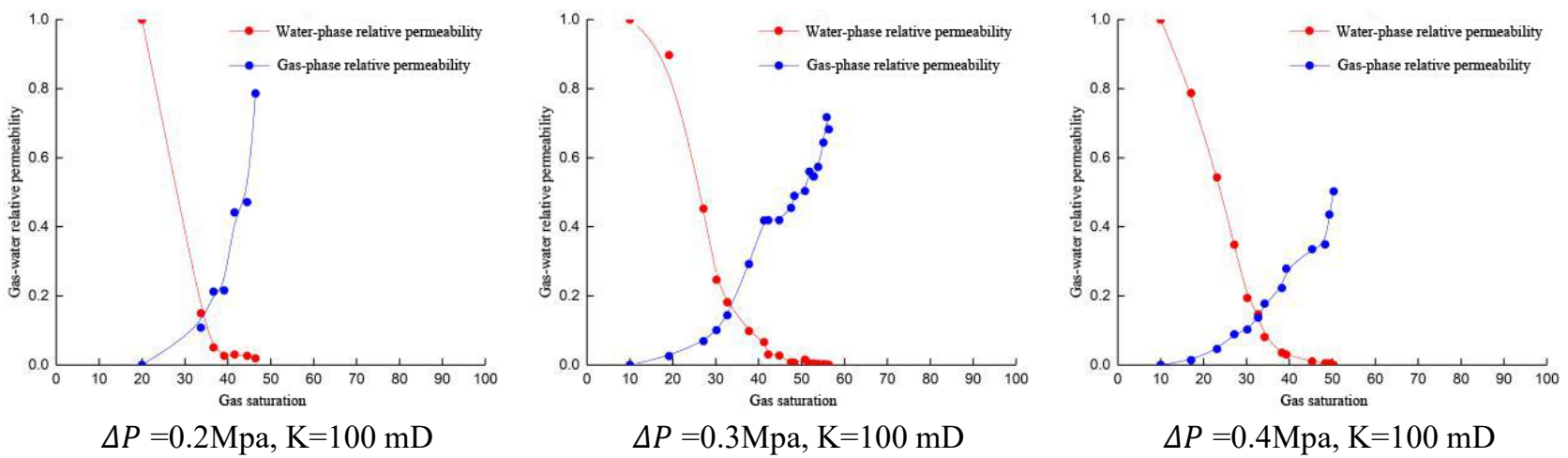

Figure 9. Comparison of relative permeability curves under a core length of $20 \mathrm{~cm}$

\section{CONCLUSIONS}

(1) In the measurement of oil-water relative permeability curves, as the core length grows, the iso-permeability points move to the right. When the core length is greater than $20 \mathrm{~cm}$, the iso-permeability points are basically stable, indicating that the core length has an impact on the measurement results of the oil-water relative permeability curves.

(2) In the measurement of gas-water relative permeability curves, under the conditions of different injection pressure, core permeability, and core length values, after the displacement starts, with the increase of gas saturation, the water-phase relative permeability curves show a steep decline in the initial stage, and the decline gradually slows down in later stage.

For low-permeability cores, when the injection pressure is constant, as the core length grows, the iso-permeability points and the iso-permeation areas show an obvious tendency of moving to the left, but such tendency is not obvious when the core length is greater than $20 \mathrm{~cm}$, and high-permeability cores do not have such characteristics, indicating that the core length has an impact on the measurement results of relative permeability curves, and the measurement results are relatively accurate when the core length is about $20 \mathrm{~cm}$. For high-permeability cores, the impact of core length on the measurement results of the gas-water relative permeability curves is not obvious.

When core permeability and core length are constant, for low permeability cores, as the injection pressure grows, the gas-water co-permeation areas increase as well, the gas-water relative permeability increases, and the curves move to the right. As for high-permeability cores, within a certain pressure range, the gas-water co-permeation areas increase; when the pressure continues to grow, the gas-water co-permeation areas do not change much.

\section{REFERENCES}

[1] Du, J., Liu, Q., Guo, P., Jiang, T., Xiong, Y., Jiang, X. (2020). Study on water displacing gas relative permeability curves in fractured tight sandstone reservoirs under high pressure and high temperature. ACS Omega, 5(13): 7456-7461. https://doi.org/10.1021/acsomega.0c00139

[2] Zhang, L.H., Tong, J., Xiong, Y., Zhao, Y.L. (2017). Effect of temperature on the oil-water relative permeability for sandstone reservoirs. International
Journal of Heat and Mass Transfer, 105: 535-548. https://doi.org/10.1016/j.ijheatmasstransfer.2016.10.029

[3] Counsil, J.R., Ramey Jr, H.J. (1982). Effects of vaporization and temperature in gas/liquid relative permeability experiments. Society of Petroleum Engineers Journal, 22(1): 108-116. https://doi.org/10.2118/9729-PA

[4] He, M., Zhou, Y., Wu, K., Hu, Y., Feng, D., Zhang, T., $\mathrm{Li}, \mathrm{X}$. (2021). Pore network modeling of thin water film and its influence on relative permeability curves in tight formations. $\quad$ Fuel, 119828. https://doi.org/10.1016/J.FUEL.2020.119828

[5] Mirzaei-Paiaman, A. (2021). New methods for qualitative and quantitative determination of wettability from relative permeability curves: Revisiting Craig's rules of thumb and introducing Lak wettability index. Fuel, 288: 119623. https://doi.org/10.1016/J.FUEL.2020.119623

[6] Esmaeili, S., Sarma, H., Harding, T., Maini, B. (2019). Review of the effect of temperature on oil-water relative permeability in porous rocks of oil reservoirs. Fuel, 237: 91-116. https://doi.org/10.1016/j.fuel.2018.09.100

[7] Wan, T., Yang, S., Wang, L., Sun, L. (2019). Experimental investigation of two-phase relative permeability of gas and water for tight gas carbonate under different test conditions. Oil \& Gas Science and Technology-Revue d'IFP Energies nouvelles, 74: 23. https://doi.org/10.2516/ogst/2018102

[8] Lai, B., Miskimins, J.L. (2010). A new technique for accurately measuring two-phase relative permeability under non-Darcy flow conditions. In SPE Annual Technical Conference and Exhibition. Society of Petroleum Engineers, 127: 398-408. https://doi.org/10.1016/j.petrol.2015.01.034

[9] Ren, X., Li, A., Fu, S., Wang, S. (2018). Experimental study on the oil-water relative permeability relationship for tight sandstone considering the nonlinear seepage characteristics. Journal of Petroleum Science and Engineering, 161: 409-416. https://doi.org/10.1016/j.petrol.2017.12.003

[10] Wang, L., He, Y., Chen, H., Meng, Z., Wang, Z. (2019). Experimental investigation of the live oil-water relative permeability and displacement efficiency on Kingfisher waxy oil reservoir. Journal of Petroleum Science and Engineering, 178: 1029-1043. https://doi.org/10.1016/j.petrol.2019.04.027

[11] Yi, M., Guo, P., Sun, L.T. (2007). An experimental study on relative permeability curve for unsteady-state gas 
displacement by water. Natural Gas Industry, 27(10): 9294. https://doi.org/10.3321/j.issn:10000976.2007.10.027

[12] Zhong, X., Du, J.F. (2013). Gas-water permeability characteristics and high temperature and high pressure experimental study. Journal of Chongqing University of Science and Technology (Natural Sciences Edition), 15(3):

70-73. https://doi.org/10.19406/j.cnki.cqkjxyxbzkb.2013.03.01 9

[13] Dong, P.C., Jiang, T.W., Tang, M.L. (2008). Relative permeability law of multiphase seepage under high temperature and pressure in a gas condensate reservoir. Chinese Journal of Rock Mechanics and Engineering, 27(11): 2244-2251. https://doi.org/10.3321/j.issn:10006915.2008.11.010

[14] Zhang, X., Yang, S.L., Li, F.F., Chen, H., Nie, X.R., Ding, J.C. (2013). Characteristics analysis of gas-water two-phase flow in volcanic gas reservoir. Fault-Block Oil and Gas Field, 20(5): 631-633. https://doi.org/10.6056/dkyqt201305021

[15] Fang, J.L., Guo, P., Xiao, X.J., Du, J.F., Dong, C., Xiong, Y.M., Long, F. (2015). Gas-water relative permeability measurement of high temperature and high pressure tight gas reservoirs. Petroleum Exploration and Development,
42(1): $\quad 92-96 . \quad$ https://doi.org/10.1016/S18763804(15)60010-6

[16] Li, C.H., Li, X.Z., Gao, S.S., Liu, H.X., You, S.Q., Fang, F.F., Shen, W.J. (2017). Experiment on gas-water twophase seepage and inflow performance curves of gas wells in carbonate reservoirs: A case study of Longwangmiao Formation and Dengying Formation in Gaoshiti-Moxi block, Sichuan Basin, SW China. Petroleum Exploration and Development, 44(6): 983992. https://doi.org/10.1016/S1876-3804(17)30110-6

[17] Sun, K., Liu, H., Wang, Y., Ge, L., Gao, J., Du, W. (2020). Novel method for inverted five-spot reservoir simulation at high water-cut stage based on time-varying relative permeability curves. ACS Omega, 5(22): 1331213323. https://doi.org/10.1021/acsomega.0c01388

[18] Zheng, Z., Ma, Q., Hu, P., Song, Y., Wang, D. (2020). Uncertainty and sensitivity analysis of relative permeability curves for the numerical simulation of $\mathrm{CO}_{2}$ core flooding. Greenhouse Gases: Science and Technology, 10(3): 519-530. https://doi.org/10.1002/ghg.1977

[19] China National Petroleum Corporation. (2008). SY/T5345-2007 Petroleum and natural gas industry standard of the people's Republic of China. Beijing: Petroleum Industry Press. 